\title{
Influência da temperatura de fermentação na formação da estrutura do miolo de pães tipo forma
}

\author{
R. A. ZAMBELLI ${ }^{1}$, D. F. PONTES ${ }^{1}$, L. F. L. HERCULANO ${ }^{1}$, E. R. PONTES ${ }^{1}$, P. E. F. \\ MELO ${ }^{1}$, D. L. BRASIL' \\ ${ }^{1}$ Universidade Federal do Ceará, Departamento de Tecnologia de Alimentos. \\ E-mail para contato: Zambelli@alu.ufc.br
}

\begin{abstract}
RESUMO - O estudo teve como objetivo estudar o efeito da utilização de diferentes temperaturas de fermentação na estrutura do miolo de pães. O experimento foi realizado em câmara de fermentação umidade relativa fixada em $70 \%$ e temperatura variando em $25,30,35,40$ e $45{ }^{\circ} \mathrm{C}$, avaliou-se através do programa Image ${ }^{\circledR}$ imagens digitalizadas de fatias de pães que foram convertidas para tons de cinza 32-bit e limiarizadas pelo algoritimo de otsu, a partir disto foram calculados os número, área, perímetro e circularidade dos alvéolos. Percebeu-se que com temperaturas superiores a $35{ }^{\circ} \mathrm{C}$ a fermentação foi mais dificultosa e isto refletiu na redução dos alvéolos de $1080\left(30{ }^{\circ} \mathrm{C}\right)$ para $540\left(45^{\circ} \mathrm{C}\right)$. Devido a isto, houve aumento na área e perímetro médio dos alvéolos, com a formação de fendas pela junção de vários alvéolos, o que refletiu nos valores de circularidades, que variou de $0,95\left(30{ }^{\circ} \mathrm{C}\right)$ a $0,83\left(45^{\circ} \mathrm{C}\right)$ se distanciando do que é considerado um círculo perfeito.
\end{abstract}

\section{INTRODUÇÃO}

De acordo com Gomez et al. (2008) o tempo e a temperatura que ocorrem o processo de fermentação podem afetar a firmeza inicial e a taxa de endurecimento de miolo de pães de trigo branco e integrais. Purhagen et al. (2011) verificaram que os parâmetros de processo e métodos de fabricação de pães influenciam no endurecimento do produto, sendo detectadas diferenças significativas entre processos realizados em laboratório e industrialmente.

A fermentação da massa é uma fase importante no processo de fabricação do pão, afeta os parâmetros do produto final, tais como textura, palatabilidade e a qualidade geral. Esta etapa é uma importante fase dependente da temperatura, em que o metabolismo de leveduras transforma hidratos de carbono assimiláveis e de aminoácidos em dióxido de carbono e álcool etílico como os principais produtos finais (Birch et al., 2013).

A fase de fermentação tem sido extensivamente estudada a partir de vários pontos de vista, todos eles tem como objetivo obter informações sobre o processo e os parâmetros de cozimento, explicando, assim, os fenômenos do processo e melhorar o conhecimento, bem como o controle sobre o produto final. A evolução dos parâmetros de qualidade, tais como o volume de massa, densidade e tamanhos e distribuição dos alvéolos e células de gás são importantes variáveis a serem controladas, uma vez que o seu comportamento tem influência sobre a qualidade do produto final (Lassoued et al., 2007; Ivorra et al., 2014).

Para avaliar microestrutura de miolo de pão, análise de imagens é uma ferramenta conveniente e útil para qualificar e quantificar as características da estrutura do miolo (Demirkesen et al., 2013). 
Diante do exposto, o trabalho tem como objetivo estudar o efeito de diferentes temperaturas durante a fermentação de massas para a produção de pães na estrutura do miolo.

O estudo tem como objetivo estudar a variação da temperatura e injeção de vapor durante o processo de fermentação com o delineamento composto central rotacional em formulações de pães tipo forma visando à otimização dos parâmetros físicos dos produtos.

\section{METODOLOGIA}

O desenvolvimento da formulação de pães tipo forma foi realizado a partir de uma formulação padrão, cuja composição é: $100 \%$ de farinha de trigo; $55-60 \%$ de água, $10 \%$ de Gordura Vegetal Hidrogenada; 5\% de açúcar, 3,3\% de fermento biológico e 2\% de sal.

\subsection{Processamento dos Pães Tipo Forma}

Os ingredientes foram pesados em balança semi-analítica separadamente. Aplicou-se o método direto, onde todos os ingredientes são colocados simlutaneamente no início da etapa de mistura, com exceção do sal e água. Eles foram misturados em misturadora de escala semiindustrial durante 1 minuto em baixa velocidade para a homogeneização dos ingredientes, em seguida foi adicionada a água e misturada por 3 minutos em velocidade média, por último foi adicionado o sal e a massa foi misturada em alta velocidade por 6 minutos até o seu completo desenvolvimento. As massas foram divididas em porções de $250 \mathrm{~g}$ e moldadas na forma de elipses manualmente. Foram colocadas em fôrmas de folha galvanizada de ferro de chapa única para pão de forma sem tampa. Em seguida, colocadas em câmara de fermentação regulada em temperaturas de $25,30,35,40$ e $45^{\circ} \mathrm{C}$ e $70 \%$ umidade relativa, durante uma hora e trinta minutos. Ao final da fermentação, as massas foram assadas sem vapor durante 20 minutos a temperatura de $220^{\circ} \mathrm{C}$ em forno elétrico de lastro Continental Advance Turbo®. Os pães foram resfriados durante uma hora em temperatura ambiente. A tabela 1 apresenta os tratamentos utilizados.

Tabela 1 - Tratamentos utilizados no estudo da fermentação em diferentes temperaturas

\begin{tabular}{ccc}
\hline Tratamento & Sigla de identificação & $\begin{array}{c}\text { Temperatura de } \\
\text { fermentação }\left({ }^{\circ} \mathbf{C}\right)\end{array}$ \\
\hline Tratamento 1 & T-25 & 25 \\
Tratamento 2 & T-30 & 30 \\
Tratamento 3 & T-35 & 35 \\
Tratamento 4 & T-40 & 40 \\
Tratamento 5 & T-45 & 45 \\
\hline
\end{tabular}

\subsection{Avaliação da estrutura do miolo dos pães tipo forma}

Análise do número de alvéolos: As estruturas dos miolos dos pães foram avaliadas através de imagens digitais segundo metodologia descrita por Rosales-Juárez et al. (2008); Gonzales-Barrón e Butler (2006) com modificações. As imagens foram obtidas por digitalização em resolução de 550 dpi em scanner HP ScanJet 2400, na área central do miolo com resolução de 900x900 pixels. As imagens obtidas foram analisadas com o software ImageJ ${ }^{\circledR} 1.47 \mathrm{v}$ (National Institute of Health, USA). As Imagens foram salvas como arquivos 
em formato de jpeg e foram cortadas para um campo de vista de 900x900 mm, as imagens coloridas capturadas foram convertidas para 8-bit em tons de cinza, onde foi realizada a limiarização por meio do algorítimo de Otsu. A partir disto, foi possível obter os valores do número de alvéolos, área e perímetro médio, além da circularidade.

\subsection{Análise Estatística}

A avaliação dos resultados da análise da estrutura do miolo foi realizada por análise de variância (ANOVA), sendo realizado teste de médias ao nível de 5\% de significância. A análise foi realizada no programa STATISTICA 7.0.

\section{RESULTADOS E DISCUSSÃO}

A tabela 2 apresenta o número de alvéolos, área e perimetro médio e a circularidade dos alvéolos obtidos através da análise de imagem.

Tabela 2 - Avaliação da estrutura do miolo dos pães tipo forma em diferentes temperaturas

\begin{tabular}{ccccc}
\hline Tratamento & $\begin{array}{c}\text { Número de } \\
\text { Alvéolos }\end{array}$ & $\begin{array}{c}\text { Área média dos } \\
\text { alvéolos }\left(\mathbf{m m}^{2}\right)\end{array}$ & $\begin{array}{c}\text { Perímetro } \\
\text { médio dos } \\
\text { alvéolos }\left(\mathbf{m m}^{2}\right)\end{array}$ & Circularidade \\
\hline $\mathbf{T - 2 5}$ & $1115^{\mathrm{a}} \pm 28$ & $215,18^{\mathrm{e}} \pm 2,18$ & $418,30^{\mathrm{e}} \pm 6,19$ & $0,98^{\mathrm{a}} \pm 0,02$ \\
$\mathbf{T - 3 0}$ & $1080^{\mathrm{a}} \pm 15$ & $384,33^{\mathrm{d}} \pm 3,99$ & $559,22^{\mathrm{d}} \pm 4,43$ & $0,97^{\mathrm{a}} \pm 0,01$ \\
$\mathbf{T - 3 5}$ & $911^{\mathrm{b}} \pm 17$ & $430,84^{\mathrm{c}} \pm 2,73$ & $643.91^{\mathrm{c}} \pm 5,28$ & $0,95^{\mathrm{a}} \pm 0,02$ \\
$\mathbf{T - 4 0}$ & $731^{\mathrm{c}} \pm 31$ & $577,31^{\mathrm{b}} \pm 4,15$ & $774,35^{\mathrm{b}} \pm 2,40$ & $0,90^{\mathrm{b}} \pm 0,02$ \\
$\mathbf{T - 4 5}$ & $540^{\mathrm{d}} \pm 19$ & $718,19^{\mathrm{a}} \pm 4,84$ & $902,89^{\mathrm{a}} \pm 4,85$ & $0,83^{\mathrm{a}} \pm 0,03$ \\
\hline
\end{tabular}

${ }^{1}$ Letras diferentes em uma mesma coluna não apresentam diferenças significativas $(\mathrm{p} \leq 0,05)$.

O número de alvéolos foi influenciado significativamente, ao nível de $5 \%$ de significância, pelo aumento da temperatura de fermentação, quando ocorreu a $25{ }^{\circ} \mathrm{C}$, foi produzido o maior número de alvéolos, de 1.115; quando houve a elevação da temperatura ocorreu menor produção das células de gás, reduzindo o número de alvéolos, que, aos $45^{\circ} \mathrm{C}$ de temperatura de fermentação, foi de apenas 540. Isto se deve ao fato de temperaturas acima de $35{ }^{\circ} \mathrm{C}$ reduzirem a capacidade fermentativa das células de levedura, dificultando e tornando mais lenta a fermentação, conforme afirma Cauvain (2009).

Segundo Almeida (2012), a formação das células de gás, cerca de $8 \%$, se forma durante a etapa de mistura da massa, onde ocorre a incorporação de ar, que, possue uma composição de $79 \%$ de nitrogênio e $21 \%$ de oxigênio, durante a fermentação este oxigênio é consumido pelas leveduras e o $\mathrm{CO}_{2}$ é difundido na massa através de um equilíbrio de fases entre a fase líquida e gasosa, posteriormente ocorre uma elevação da pressão e o $\mathrm{CO}_{2}$ passa totalmente para o estado gasoso, elevando o volume dos pães e fornecendo pressão às células de gás, futuros alvéolos, que serão preenchidos com o gás carbônico e expandidos durante o forneamento, levando à sua formação. Portanto, com a elevação da temperatura acima de 35 ${ }^{\circ} \mathrm{C}$, houve redução na produção de gás carbônico devido à redução da atividade da levedura. 
Como resultado de uma fermentação dificultosa, houve aumento da área média dos alvéolos, foram obtidos alvéolos com área de $215,18 \mathrm{~mm}^{2}$ à $25^{\circ} \mathrm{C}$ a $718,19 \mathrm{~mm}^{2}$ quando a temperatura foi de $40{ }^{\circ} \mathrm{C}$, todas as áreas médias dos alvéolos apresentaram diferenças significativas. Resultado semelhante foi obtido para o perímetro, que variou de $418,30 \mathrm{~mm}^{2}$ para $25^{\circ} \mathrm{C}$ a 902,89 para $40{ }^{\circ} \mathrm{C}$, também ocorrendo diferenças significativas em todas as temperaturas estudadas. Shi et al. (2013) observaram aumento na área e no perímetro de alvéolos de pães adicionados de filmes de zeína

A circularidade é o parâmetro que mede o quanto os alvéolos se aproximam ou não de um círculo, seus valores a variam de 0 a 1, onde representa o valor de um círculo perfeito (ROSELL e GOMEZ, 2007). A circularidade foi influenciada pela temperatura de fermentação, havendo sua redução. Variou de 0,98 para $25{ }^{\circ} \mathrm{C}$ a 0,83 para $40{ }^{\circ} \mathrm{C}$. Matos e Rosell (2012) encontraram valores de circularidade de pães sem glúten variando de 0,64 a 0,81 ; inferiores no estudo com variação da temperatura de fermentação, o fato de ter sido utilizado pães sem glúten contribuiu para a formação de um miolo com menor uniformidade e mais denso, tendo, portanto, menores valores de circularidade. Não houve diferenças significativas entre a circularidades dos alvéolos dos pães fermentados à $25^{\circ} \mathrm{C}, 30^{\circ} \mathrm{C}$ e 35 ${ }^{\circ} \mathrm{C}$.

As figuras 1 e 2 mostram a estrutura do miolo para massas fermentadas à $25^{\circ} \mathrm{C}$.

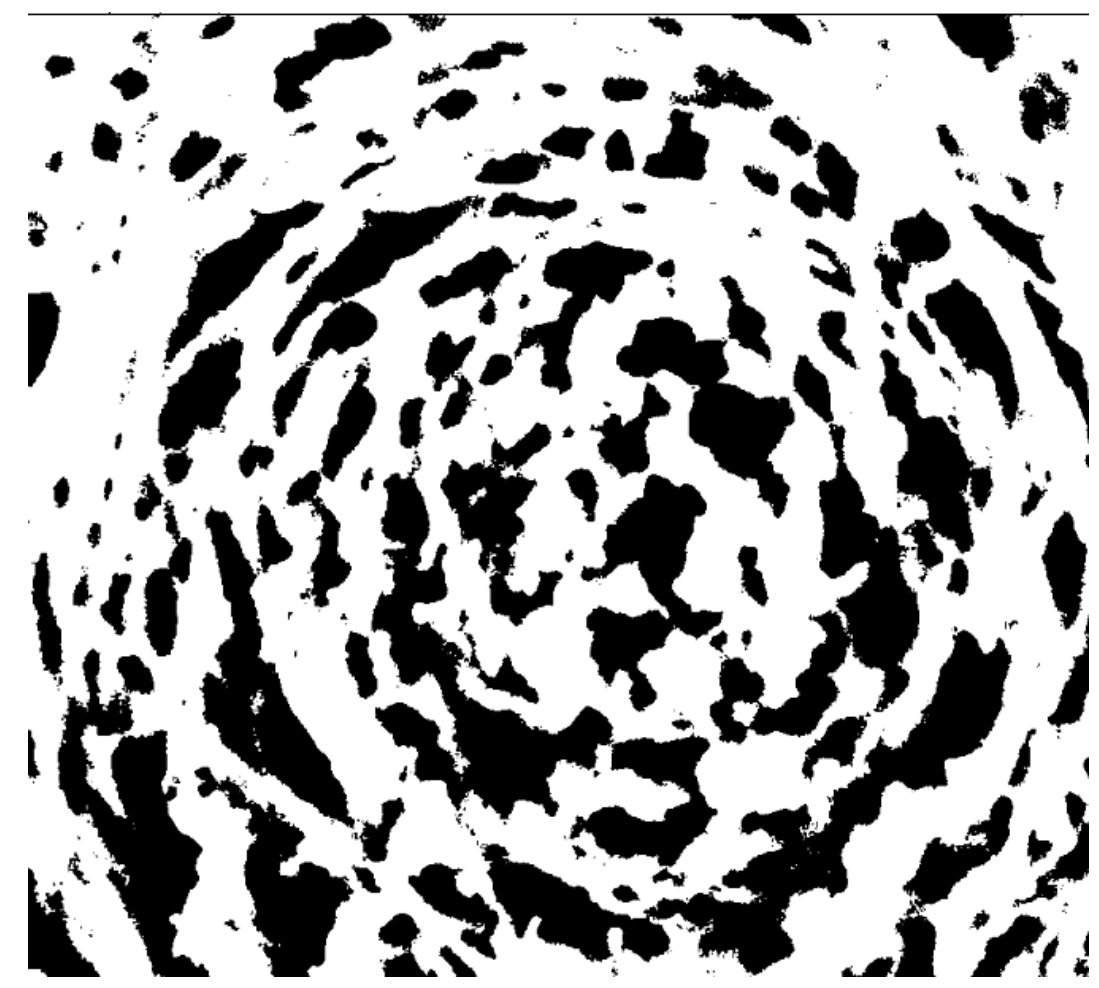

Figura 1 - Estrutura do miolo de pão tipo forma fermentado à temperatura de $30{ }^{\circ} \mathrm{C}$

Na figura 1 observa-se boa distribuição dos alvéolos produzidos durante o processo fermentativo. Os pães fermentados à temperatura de $30{ }^{\circ} \mathrm{C}$ apresentaram conformação circular 
para a distribuição alveolar, onde, segundo Demirkesen et al., (2013) este comportamento fornece um equilíbrio entre as características físicas, como volume específico e densidade e as propriedades de textura instrumental e sensorial, caracterizando pães de boa qualidade

A figura 2 apresenta a estrutura do miolo de pão tipo forma fermentado à temperatura de $40{ }^{\circ} \mathrm{C}$.

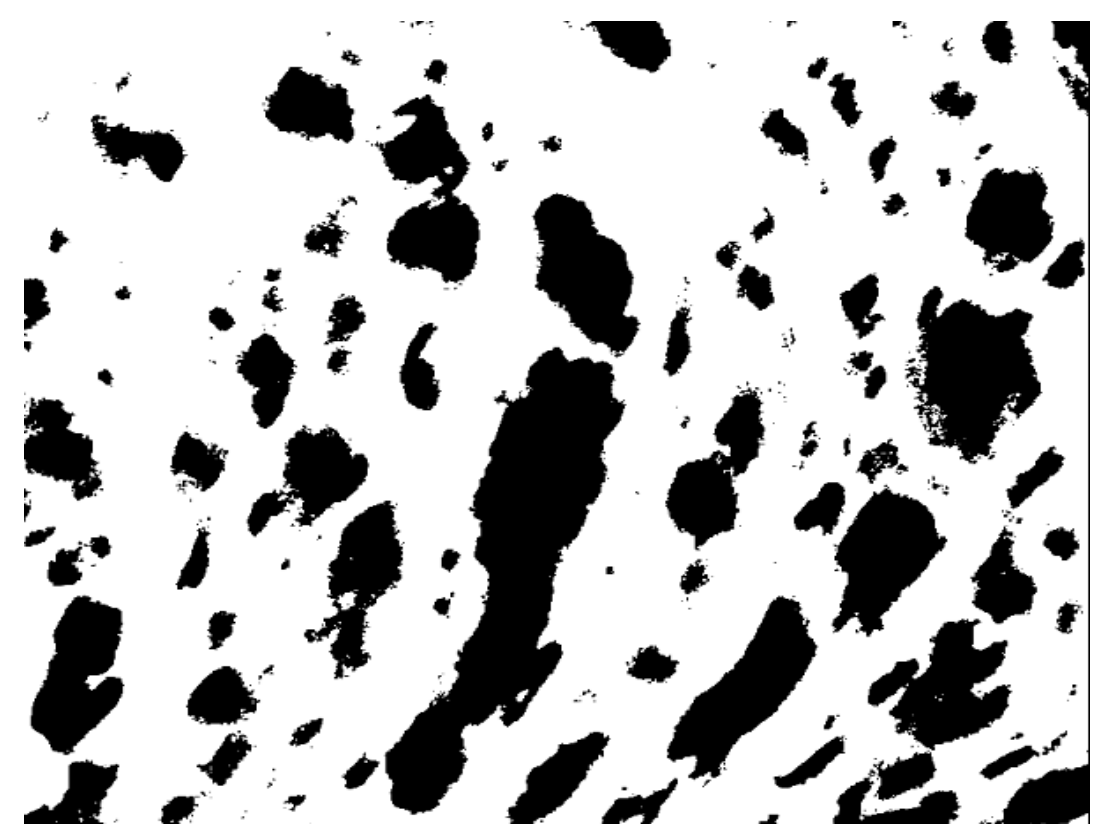

Figura 2 - Estrutura do miolo de pão tipo forma fermentado à temperatura de $40{ }^{\circ} \mathrm{C}$

Na figura 2 observou-se a formação de menor número de alvéolos, caracterizando miolo mais denso, sendo prejudicial à qualidade dos pães, apresenta a presença de alvéolos grandes, no formato de fendas, o que caracteriza um processo fermentativo mal conduzido, devido à temperatura elevada não houve desenvolvimento pleno da fermentação, ocasionando modificações na estrutura do miolo dos pães. De acordo com Gondek et al., (2013), a qualidade do pão é reflexo de suas características estruturais do miolo e de textura, no qual a porosidade deste é de fundamental importância.

Zambelli (2014) relacionou análises de imagem de pães tipo forma incorporados com tomate em pó e polidextrose com a textura instrumental e sensorial, observou que o aumento da densidade do miolo do pão na análise de imagem foi acompanhado do aumento da gomosidade, dureza e coesividade dos pães, sensorialmente, apresentou redução nos valores hedônicos.

\section{CONCLUSÃO}

Verificou-se que temperaturas de fermentação acima de $35^{\circ} \mathrm{C}$ proporcionou a redução do número dos alvéolos, bem como o aumento da sua área e perímetro médio, apresentando redução na sua circularidade, caracterizando pães de menor qualidade. 


\section{REFERÊNCIAS}

ALMEIDA, E. L.; CHANG, Y. K. Influence of different enzymes during the frozen storage of pre-baked French bread elaborated with whole-wheat flour. J. Food. Proc. Pres., v. 67, n. 2, p. 38-45, 2012.

BIRCH, A. N.; PETERSEN, M. A.; ARNEBORG, A.; HANSEN, A. G. Influence of commercial baker's yeasts on bread aroma profiles. Food Res. Int., v. 52, p. 160-166, 2013. CAUVAIN, S. P.; YOUNG, L. S. Tecnologia da Panificação. Barueri, São Paulo: Ed. Manole, 2009. 418 p.

GOMES, M.; OLIETE, B.; PANDO, V.; RONDA, F.; CABALLERO, P. A. Effect of fermentation conditions on bread staling kinetics. Eur. Food. Res. Intern., v. 226, p. 13791387, 2008.

GONDEK, E.; JAKUBCZYK, E.; HEREMANS, E.; VERLINDEN, B.; HERTOG, M.; VANDENDRIESSCHE, T. Acoustic, mechanical and microstructural properties of extrused crisp bread. J. Cer. Sci., v. 58, p. 132-139, 2013.

GONZALES-BARRÓN, U.; BUTLER, F. A comparison of seven thresolding techniques with the k-means clustering altorithm for measurement of bread-crumb features by digital image analysis. J. Food. Eng., v. 74, n. 2, p. 268-278, 2006.

IVORRA, E.; AMAT, S. V.; SÁNCHEZ, A. J.; BARAT, J. M.; GRAU, R. Continuos monitoring of bread dough fermentation using a 3D vision structured light technique. J. Food. Eng., v. 130, p. 8-13, 2014.

LASSOUED, N.; BABIN, P.; DELLA VALLE, G.; DEVAUX, M. F. REGUERRE, A. L. Granulometry of bread crumb grain: contributions of 2D and 3D image analysis at different scale. Food Res. Int., v. 40, p. 1087-1097, 2007.

MATOS, M. E.; ROSELL, C. M. Relationship between instrumental parameters and sensory characteristcs in gluten-free breads. Eur. Food. Res. Technol., v. 235, n. 1, p. 107-117, 2012.

PURHAGEN, J. K.; SJÖ, M. E.; ELIASSON, A. C. The use of normal and heat-treated barley flour and waxy barley starch as anti-staling agents in laboratory and industrial backing processes. J. Food. Eng., v. 104, p. 414-421, 2011.

ROSALES-JUÁREZ, M.; GONZÁLEZ-MENDONZA, B.; LÓPEZ-GUEL, E.; LOZANOBAUTISTA, F.; CHANONA-PÉREZ, J.; GUTIÉRREZ-LOPES, G.; FARRERA-REBOLLO, R.; CALDERÓN-DOMÍNGUEZ, G. Changes on dough rheological characteristics and bread quality as a result of the addition of germinated and non-germinated soybean flour. Food Biop. Technol., v. 1, n. 2, p. 2008.

ROSELL, C. M.; GÓMEZ, M. Freezing in breadmaking performance: frozen dough and partbaked bread. Food Rev. Int., v. 23, n. 2, p. 303-139, 2007. 
SHI, K.; YU, H.; JIN, J.; LEE, T. Improvement to baking quality of frozen bread dough by novel zein-based ice nucleations film. J. Cer. Sci., v. 57, n. 3, p. 430-436, 2013.

ZAMBELLI, R. A. Desenvolvimento de massas congeladas de pães tipo forma contendo ingredientes funcionais. 205 f. Dissertação. (Mestrado em Ciência e Tecnologia de Alimentos), Universidade Federal do Ceará, Fortaleza, 2014. 